\title{
O Que É uma Exposição de Matemática?
}

\section{What Is a Mathematical Exhibition?}

RESUMO

Este artigo começa por discutir o que se espera de uma exposição sobre matemática e descreve o percurso da Matemateca, do Instituto de Matemática e Estatística da USP, na formação de um acervo de objetos matemáticos ao longo de aproximadamente dez anos, bem como a evolução da concepção de uma exposição voltada para o público em geral, mas com foco nos estudantes de todos os níveis. São dados vários exemplos de peças e mostradas possíveis abordagens para atrair o visitante, inclusive pensando no leitor deste artigo que não tenha familiaridade com esse tipo de exposição. Além disso, é dada uma visão do panorama internacional no que tange a exposições de matemática, de forma a permitir ao leitor inserir a Matemateca nesse contexto. Finalmente, são considerados alguns caminhos a serem seguidos na continuidade e aprimoramento desse trabalho.

Palavras-chave: Exposição. Matemática. Exposição Interativa. Divulgação Científica. Popularização da Matemática.

\section{ABSTRACT}

This article begins by discussing what is expected of a math exhibition and describes the work of Matemateca's team over approximately ten years in forming a collection of mathematical objects in the Instituto de Matemática e Estatística da USP. It also describes the evolution of the underlying concept of this exhibition aimed at the general public, but focused on students of all levels. Several examples of exhibits are given as well as some possible approaches to attract the visitor. It is also given an overview of the international scene with respect to mathematical exhibitions to allow the reader to place the Matemateca in this context. Finally, some paths are considered for the continuity and improvement of this work.

Keywords: Exhibition. Mathematics. Interactive Exhibition. Science Popularization.

EDUARDO COLLI E

DEBORAH RAPHAEL

Universidade de São Paulo. Instituto de Matemática e Estatística, São Paulo, Brasil 
Mathematics Popularization.

\section{INTRODUÇÃO}

"Matemática" é uma palavra que tem peso na fala social e evoca sentimentos fortes, quase sempre provocados por sensações passadas que podem ser de repulsa e dificuldade ou, no outro extremo, de fascínio e admiração, mas têm em comum o fato de serem usualmente criadas a partir de uma visão apenas parcial do que é a Matemática. Compreender as razões pelas quais a Matemática costuma ser percebida de forma dramática (e frequentemente negativa) é assunto que envolve várias áreas do conhecimento e inclui questões que vão desde as eminentemente práticas que aparecem no dia a dia da sala de aula até questões filosóficas sobre a natureza do conhecimento matemático, passando também por estudos de ciência cognitiva, neurociência e psicologia [14]. Mesmo sem compreender os mecanismos e processos que acabam por construir uma imagem individual da Matemática, é fácil constatar que é usualmente baseada em uma faceta muito limitada dessa ciência. Afinal, o que estuda a Matemática? Essa pergunta parece muito mais difícil do que se trocarmos a palavra Matemática por Biologia ou por Física. Cabe ao profissional de matemática refletir sobre a resposta apropriada e o papel de preencher lacunas de comunicação que foram sendo criadas entre os que praticam ou usam a Matemática e o público em geral.

Revelar ao público aspectos pouco conhecidos de uma área da Ciência é função do divulgador de ciência. Há várias formas de divulgação científica: a do especialista que se dispõe a escrever em linguagem acessível, a do jornalista que se dedica a destrinchar algum tema partindo do ponto de vista do leigo, as palestras, os vídeos e filmes e, sem querer esgotar essa pequena lista, as exposições científicas. Originalmente restritas às exibições de acervo e aos museus de "história natural", as exposições científicas evoluíram ao longo do século XX para formas mais atraentes de comunicação com o público, que frequentemente se valem de dispositivos com os quais os visitantes podem interagir.

Todas essas formas de divulgação científica estão presentes na divulgação de matemática, embora aparecendo sempre com considerável atraso em relação às demais áreas científicas. Algumas merecem ser destacadas. Entre os jornalistas, James Gleick aprofundou-se nos temas da Teoria do Caos [9] e da Teoria da Informação [10] e, mais recentemente, Alex Bellos deu uma visão de aspectos históricos e curiosos com uma costura bastante envolvente [2]. O agora falecido colunista da revista Scientific American por muitos anos, Martin Gardner, também se destaca entre os não matemáticos com diversas coletâneas de artigos tanto de matemática recreacional como de divulgação de assuntos de pesquisa [8]. Já entre os matemáticos, impossível não citar o pioneiro livro de Courant e Robbins [3], o prolífico Ian Stewart, que tem dezenas de livros publicados $[7,8]$, e o português Nuno Crato, atual ministro da Educação e Ciência de Portugal, segue o estilo de Gardner e Stewart numa contribuição em língua portuguesa $[9,10]$. A lista é longa e mereceria uma resenha à parte. Finalizamos lembrando dois brasileiros de importância histórica: Monteiro Lobato escreveu 
Aritmética da Emilia, publicado em 1935 e o cativante Júlio César de Mello e Souza, mais conhecido pelo seu heterônimo Malba Tahan, escreveu vários livros de entretenimento matemático - O Homem que Calculava foi publicado pela primeira vez em 1938 e continua a ser reeditado até hoje.

No universo expositivo, vale a pena pontuar o enorme boom de modelos destinados à ilustração concreta de conceitos matemáticos que ocorreu no final do século XIX. Essa moda fez parte de um movimento mais abrangente que incluía demonstrações públicas de fenômenos físicos tais como raios $\mathrm{X}$, descargas elétricas ou as placas de Chladni, estas últimas abordadas logo adiante neste artigo [13]. No que tange à Matemática, a produção de modelos concretos arrefeceu no século XX, talvez fruto da busca pela consolidação dos fundamentos da Matemática e da preponderância de David Hilbert e da escola formalista que teve, graças aos livros didáticos do grupo Bourbaki, grande influência no ensino da Matemática [12, 13]. De forma geral bastante radicais na ênfase do arcabouço lógico-dedutivo, os livros do grupo Bourbaki evitam tudo que não seja "puro", como ilustrações, desenhos, exemplos de aplicações etc.

Desde os anos 1960, a Matemática se faz presente na maioria das grandes exposições de ciência europeias e norte-americanas. Destaca-se a exposição pioneira do escritório de design do casal Charles e Ray Eames, patrocinada pela IBM e denominada "Mathematics: a World of Numbers... and Beyond", inaugurada no início da década de 1960 no California Museum of Science and Industry. Duas cópias ainda se encontram expostas, uma no New York Hall of Science e a outra no Museum of Science em Boston. A exposição é muito bonita e apresenta soluções inovadoras e propostas ousadas para a época. Embora tendo várias peças contemplativas, no estilo dos modelos do final do século XIX, algumas atrações são interativas no sentido moderno. É notável o fôlego desta exposição que, mantido o projeto original, ainda continua a encantar o público. Em meados da década de 1990 foi inaugurada a exposição de Matemática do Musée de la Science et de l'Industrie, do Parc La Villete trazendo novos elementos e mudando o panorama da divulgação da matemática. Aqui, os textos são mais profundos que aqueles dos Eames e fica claro que foram escritos por matemáticos. $\mathrm{O}$ que se ganha em elaboração se perde em alcance - é duvidoso que o público em geral compreenda a linguagem mais hermética. Por outro lado, quase todas as atrações oferecem algum grau de interatividade, o que parece convidar o visitante a "chegar mais perto".

Pode-se dizer que, a partir daí, foi dado o "tom" de uma exposição de matemática: tópicos interessantes, em geral não abordados diretamente no ensino médio ou mesmo na graduação, mostrados por meio de uma instalação interativa e com alguma explicação escrita que varia de profundidade dependendo do público que se espera atingir. A interatividade pode fazer uso de meios mecânicos, elétricos, eletrônicos ou "tecnológicos", no sentido de trabalhar com artifícios computacionais que combinam sensores de movimento, análise de imagens em tempo real e projeções mapeadas sobre objetos diversos. Testemunha dessa tendência foi a abertura, no final de 2012, do MoMath, o Museu de Matemática de Nova Iorque, destinado a um público mais infantil que o La Villete e com propostas mais lúdicas, mas mantendo o mesmo tipo de percurso com nichos temáticos. 
Entre o La Villete e o MoMath surgiram outras iniciativas pelo mundo, por exemplo, na Alemanha, o Mathematikum, em Giessen, e o Erlebnisland Mathematik, em Dresden; na Espanha o MMACA, de Barcelona. No Brasil, a Matemateca surge em meados de 2003 e possui hoje o mais importante acervo brasileiro de objetos matemáticos.

É importante enfatizar a consistência que essas iniciativas de divulgação em matemática vêm adquirindo. Isso se comprova pela organização do primeiro encontro internacional de profissionais da área (denominado MATRIX - Mathematics Awareness, Training, Resources \& Information Exchange, que ocorreu em setembro de 2014, em Dresden, Alemanha) e também por novas iniciativas na criação de exposições de matemática e centros de matemática. No Science Museum, de Londres, deverá ser aberta ao público em 2016 uma ambiciosa exposição de matemática com orçamento anunciado de cinco milhões de libras [17] e, na França, foi inaugurada em setembro de 2012 a Maison des Mathématiques et de l'Informatique de Lyon.

\section{A MATEMATECA}

Na Universidade de São Paulo, o Prof. Ernst Hamburger, então diretor da Estação Ciência, promoveu um acordo com a Cité des Sciences et de l'Industrie de la Villette, replicando e traduzindo grande parte do material da exposição francesa MATH 2000. Posteriormente, foi agregado material concebido com a colaboração do Prof. Sergio Muniz Oliva, docente do IME-USP. Esta exposição está agora no Parque CienTec, mas itinerou pelo IME-USP em 2002 e serviu de inspiração e impulso para a criação da Matemateca.

Influenciada duplamente pela exposição do La Villete - tanto sua versão original quanto sua mostra itinerante - a Matemateca surge em 2003, por iniciativa destes autores e de outros professores do Instituto de Matemática e Estatística da USP (IME)* O primeiro passo foi o início da construção de uma coleção de objetos de natureza interativa, cada um deles ilustrando uma ideia matemática. Essa coleção serviria a dois propósitos: constituir ao mesmo tempo uma exposição (fosse ela fixa ou itinerante) voltada para um público amplo e um arquivo de materiais didáticos a serem utilizados pelos professores do IME nas aulas de graduação. É bom enfatizar que o IME tem cerca de 1800 alunos nos seus seis cursos de graduação e, além disso, oferece disciplinas a todos os cursos de exatas do campus Butantã, o que acrescenta mais alguns milhares de estudantes em seus cursos.

Por conta dessa intenção didática, os primeiros financiamentos para a confecção do acervo da Matemateca vieram da Pró-Reitoria de Graduação da USP, por meio do Programa de Reequipamento de Laboratórios Didáticos (ProLab). Mais adiante, por conta do aspecto de divulgação, a Matemateca teve o apoio do CNPq, por meio de

\footnotetext{
*Sonia Regina Leite Garcia e Elvia Mureb Sallum; passaram também pela equipe Alexandre Roma, Rosa Maria Barreiro Chaves e Barbara Corominas Valério; e colaboram atualmente Viviana Giampaoli e Leônidas da Silva Brandão, além de Sonia Regina Leite Garcia e Elvia Mureb Sallum que sempre participaram.
} 
dois projetos, bem como da Pró-Reitoria de Cultura e Extensão da USP, por meio de seu programa de Fomento à Cultura e Extensão e de bolsas do programa Aprender com Cultura e Extensão.

Quando a coleção tomou corpo, iniciaram-se as primeiras experiências expositivas. O início foi "em casa", em outubro de 2004, durante a I Semana da Licenciatura do IME-USP. Várias outras se seguiram, no IME e em outros lugares, sempre associando público universitário a visitas escolares agendadas, com monitoria dos alunos de graduação e de pós-graduação do IME. As exposições fora do Instituto em geral se associam a eventos: a título de exemplo, a Matemateca expôs nas Bienais da Sociedade Brasileira de Matemática de Salvador, Goiânia e Maringá (2004, 2006 e 2008) e na reunião da SBPC de 2008, na Unicamp. Apresentou-se também a convite, como mostra temporária, no Museu Exploratório de Ciências da Unicamp, em 2012, e no Centro de Difusão Científica e Cultural da USP, em São Carlos, em 2013. Em novembro de 2014, parte do acervo foi exibida no saguão de entrada da Reitoria da USP numa exposição conjunta com a Maison des Mathématiques et de l'Informatique de Lyon; essa exposição ficou aberta por um mês (Figuras 1 e 2).
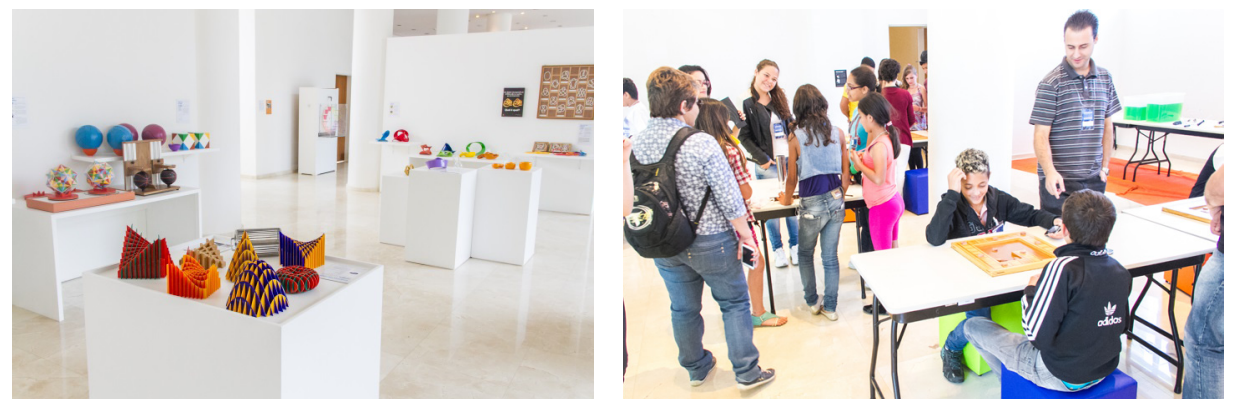

No âmbito institucional, a Matemateca se formalizou no IME como um "centro", o Centro de Difusão e Ensino Matemateca. Tendo criado expertise na criação e na confecção de material concreto para a divulgação de matemática, agregou às suas missões iniciais tornar-se referência no uso de objetos concretos para fins educativos e motivacionais nessa área. Uma das principais ações nesse sentido foi ter se associado, por intermédio do Prof. Artur Rozestraten, ao Laboratório de Modelos e Ensaios (LAME), da Faculdade de Arquitetura e Urbanismo (FAU) da USP. Dessa parceria já nasceu uma disciplina de graduação, denominada "Matemática, Arquitetura e Design”, em que alunos do IME e da FAU planejam e executam, em grupos, objetos concretos que carregam consigo conceitos matemáticos, tendo a Matemateca como referência.

\section{EXEMPLOS}

Para melhor compreender a natureza dos objetos expostos, passamos a tratar alguns exemplos. Nada substitui a real vivência do contato físico com as peças, mas ao menos
Figuras 1 e 2 - Exposição da Matemateca em novembro e dezembro de 2014, no prédio da Reitoria da USP. 
a descrição de algumas delas deverá aproximar o leitor do que é a exposição da Matemateca. Outros exemplos também serão mencionados nas próximas seções.

Placas de Chladni - Este experimento foi inventado, há cerca de 200 anos, por Ernst F. F. Chladni, da Saxônia. Ele permite visualizar os diferentes modos de vibração das placas metálicas. $\mathrm{O}$ arco do violino provoca a vibração da placa e a areia se deposita sobre os pontos que permanecem parados (pontos nodais) formando belos desenhos: as Figuras de Chladni (Figuras 3 e 4). Há um episódio curioso envolvendo esse experimento: Napoleão Bonaparte ficou tão intrigado com ele que ofereceu 3.000 francos pelo desenvolvimento de uma teoria matemática satisfatória das vibrações de uma placa. Esse prêmio coube a Sophie Germain, frequentemente citada como exemplo da presença feminina na Matemática.

Figuras 3 e 4 - Figuras de Chladni criadas pela serragem sobre placas metálicas que vibram sob a passagem de um arco de violino em suas

laterais.
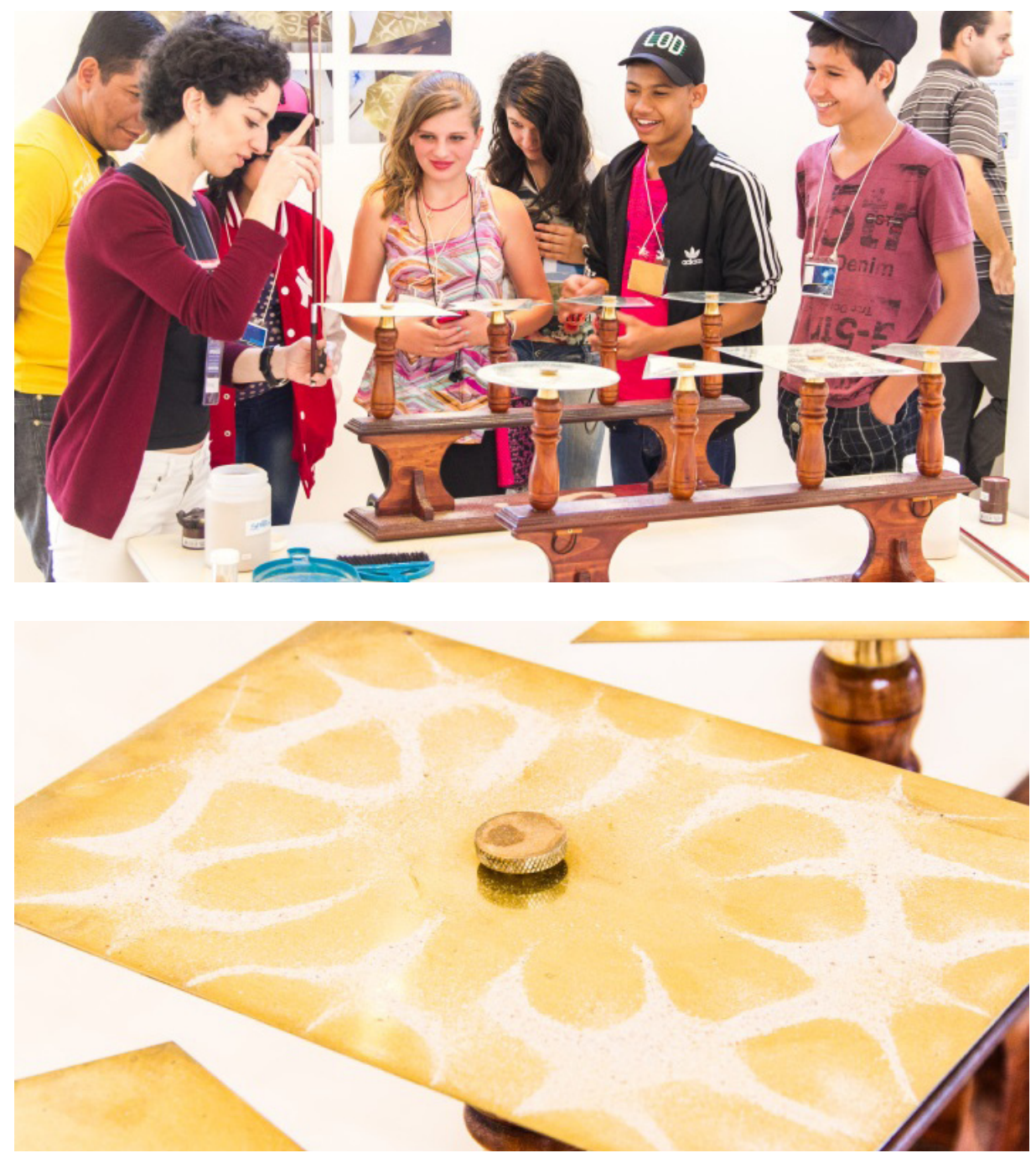
O tratamento matemático deste problema não é simples. Um modelo aproximado para descrever tais vibrações é o mesmo da membrana vibrante, para a qual se costuma usar a equação de onda. Os conceitos envolvidos são avançados e aparecem somente nos cursos de exatas como Matemática, Física e Engenharia. São, porém, centrais, pois os fenômenos ondulatórios estão presentes em toda parte e podem ser explorados de diversas maneiras na tecnologia: rádio e televisão são exemplos, assim como todas as formas de exames diagnósticos de imagem.

Essa atração ilustra a forte conexão da Matemática com a Física. A Matemática é a linguagem que permite descrever os fenômenos físicos, e foi a compreensão dessa relação que impulsionou o desenvolvimento das ciências físicas a partir de meados do século XVII. Mas a recíproca também foi verdadeira: a necessidade de criar ferramentas que pudessem lidar com toda uma nova gama de fenômenos levou a uma enorme expansão do conhecimento matemático.

Poliedro flexível - Trata-se de um poliedro feito de faces rígidas, mas ao ser manipulado, ele se mexe! Embora as faces sejam rígidas, as arestas flexionam como se fossem dobradiças (Figura 5).

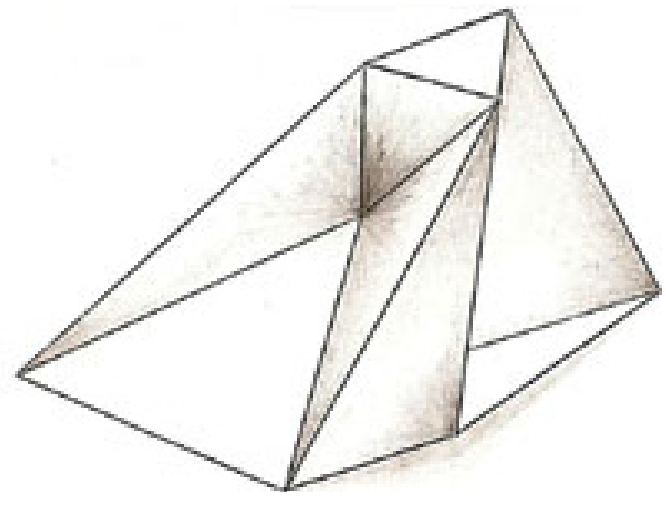

Figura 5 - Desenho de um poliedro flexível: apesar de suas faces serem triângulos rígidos, suas arestas articulam as faces entre si, criando a sensação de uma estrutura mole.

Isto pode não surpreender à primeira vista, mas é uma conquista recente da geometria. Em 1813, Augustin-Louis Cauchy provou que um poliedro convexo não pode ser flexível, mas ficou a pergunta se isso seria possível com poliedros não convexos. Foi somente em 1977 que Robert Conelly encontrou o primeiro exemplo de um poliedro não convexo e flexível. $\mathrm{O}$ objeto apresentado na exposição foi concebido por Klaus Steffen alguns anos depois.

Porém o que ilustra a capacidade inesgotável de se fazer perguntas e de se buscar respostas, é o problema conhecido como conjectura do fole: especulava-se que um poliedro flexível deveria ter volume constante. A resposta afirmativa foi dada por Conelly em 1997. Em termos concretos, significa que se abrirmos um buraco em uma das faces, o movimento do poliedro nem expelirá nem sugará ar (e, portanto, não serviria como um fole).

Ladrilhamentos - Em uma mesa (Figura 6), são expostos inúmeros polígonos de acrílico colorido, esses são os ladrilhos. A proposta é criar maneiras de ladrilhar o plano, 
isto é, preencher o plano com os polígonos, sem superposições ou buracos. Essa técnica já é usada em uma grande variedade de situações: papéis de parede, pisos decorativos com cerâmicas ou pedras, pisos e forros de madeira, estamparia de tecidos, malharias e crochês, no empacotamento ou empilhamento de objetos iguais etc.

Figura 6 - Mesa de

ladrilhos. Os visitantes podem tanto criar

à vontade quanto

tentar responder às perguntas propostas.

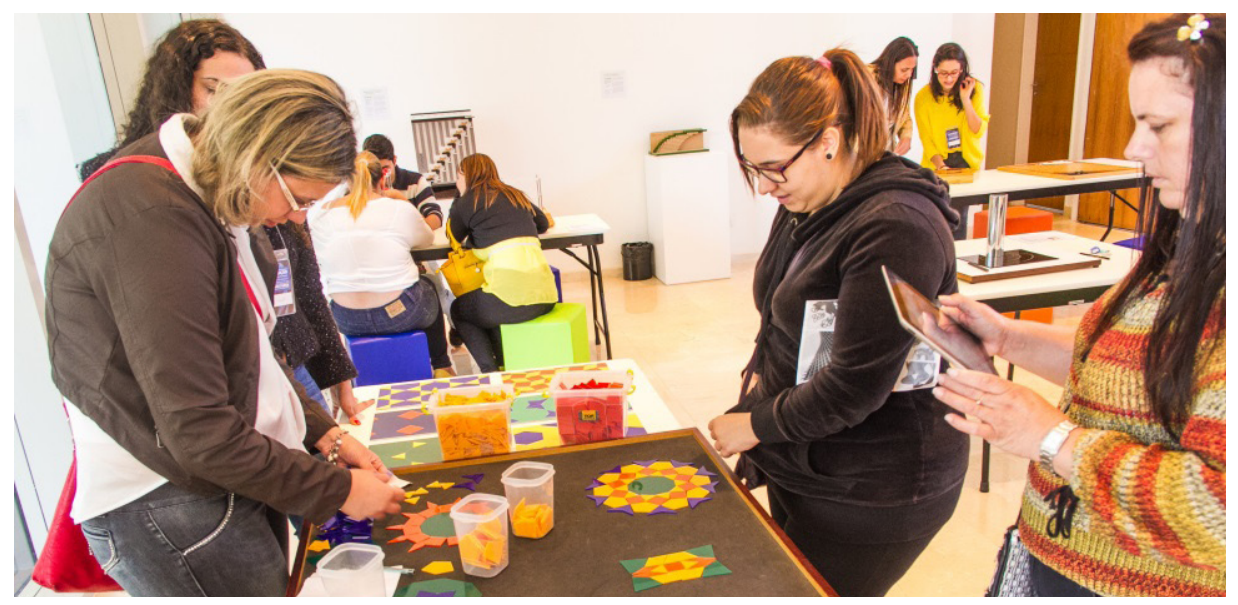

Com a variedade de ladrilhos disponíveis é possível explorar vários conteúdos matemáticos. Por exemplo, é possível identificar 11 tipos de ladrilhamentos que usam polígonos regulares e mantêm a mesma distribuição de peças em cada vértice. Esses são os únicos possíveis. Curiosamente, nenhum deles permite o uso de pentágonos regulares. Usando ladrilhos poligonais (regulares) de um único tipo só possibilita três ladrilhamentos: com triângulos equiláteros, com quadrados e com hexágonos regulares. Além disso, não é difícil ver que qualquer quadrilátero serve para fazer um ladrilhamento do plano. Já os mosaicos de Penrose trazem um conteúdo mais sofisticado e usam dois polígonos especiais, o "papagaio" e a "asa delta", que determinam uma infinidade de ladrilhamentos do plano, nenhum deles pela repetição de um mesmo motivo - são os chamados ladrilhamentos aperiódicos. Todo ou parte desse conteúdo pode ser explorado na forma de desafios ou ainda o visitante pode brincar a vontade com os ladrilhos, formular suas próprias perguntas e descobrir (ou não) as respostas.

Essas três atrações ilustram alguns dos aspectos da interatividade dos objetos. Não há muito o que fazer com o poliedro flexível, a não ser pegá-lo e se surpreender com sua maleabilidade. Um arquiteto certa vez nos fez saber de seu susto ao sentir a flexibilidade da peça, ainda mais porque se espera de uma estrutura formada por triângulos rígidos a firmeza de uma edificação!

Aliás, na exposição mesmo os objetos estáticos, de pura contemplação, podem sempre ser manipulados, de forma que a observação da exposição não é apenas visual, mas também tátil.

Nos ladrilhamentos, há tanto a liberdade de uma exploração artística das diferentes composições possíveis quanto a opção de investigar as questões matemáticas propostas. Nos dois casos, a interação há de ser feita com mais vagar, diferentemente 
de peças como o poliedro flexível. Em visitas escolares, é comum juntar um grupo de meninas em torno da mesa, que se sentam nos banquinhos disponíveis e ali "se esquecem da vida"

Se nos ladrilhamentos o que define o possível e o impossível está na argumentação geométrica, nas placas de Chladni a matemática subjacente é mais intrincada e escondida. Mesmo assim, e talvez até por causa disso, é fascinante testar as diversas placas e posições do arco, que geram inúmeras figuras bonitas e diferentes entre si. $O$ fato de ter um timbre sonoro associado ao desenho na placa já traz um encantamento. Mesmo os professores da equipe e os monitores mais experientes costumam se surpreender com figuras que pareciam não ter visto antes.

\section{DIVERSIDADE DE ABORDAGEM}

Um momento muito emblemático da sequência de exposições da Matemateca veio logo em seu início, em abril de 2005, quando participou, junto com a Estação Ciência, do IV Congresso Mundial de Centros de Ciência, ocorrido no Rio de Janeiro. Dezenas de expositores do mundo inteiro se instalaram no Rio Centro e, durante uma semana, receberam dezenas de milhares de visitantes, avulsos ou em turmas escolares. A Matemateca ainda mal havia definido e testado a idade mínima de seu público, que viria a ser, idealmente, de 11 anos, e se deparou com crianças de 4, 5 ou 6 anos se interessando por peças que remetem a assuntos avançados de graduação ou até de pós-graduação!

Com essa experiência, não demorou para que a equipe concluísse que, mais ainda do que já era esperado, não havia limitações importantes para a abordagem de assuntos avançados ao público leigo. Para tanto, era necessário investigar aspectos mais acessíveis de cada atração e propor abordagens quase que "sob medida" para cada tipo de visitante.

Para ilustrar essa ideia da diversidade de abordagem para uma mesma atração, vale a pena deter-se em um exemplo: as Montanhas de Areia. Tem-se à disposição um conjunto de placas planas, em diferentes formatos. Apoiando-se uma placa sobre pequenos suportes, seu bordo fica livre no ar. Nessa posição, despeja-se areia colorida sobre a placa, até que a montanha estabilize, isto é, até que qualquer areia acrescentada deslize para fora da placa (Figuras 7 e 8 ).
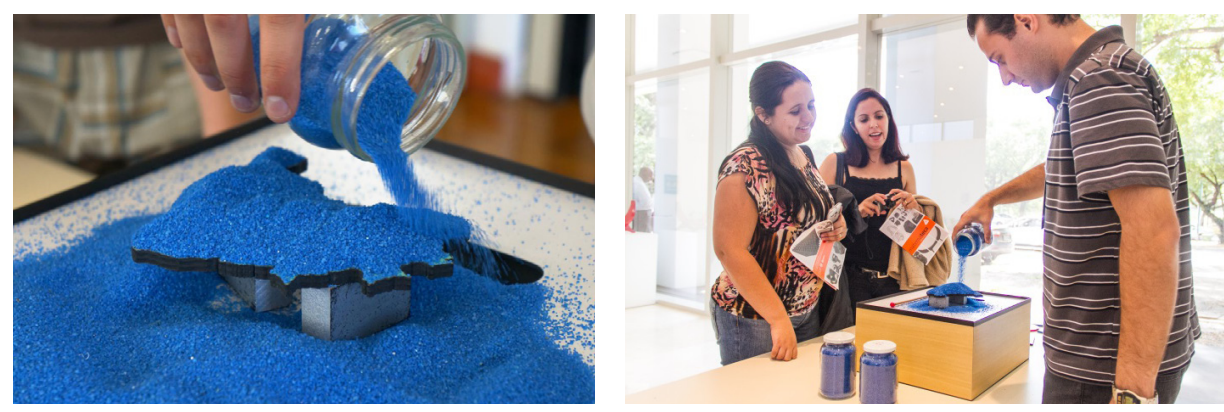

Figuras 7 e 8 - Montanhas de areia: despeja-se areia seca sobre uma placa com a intenção de entender como se relaciona a forma da montanha com a forma da placa. Nestas fotos, a forma é o mapa do Brasil e o ponto mais alto da montanha indica o centro geográfico. 
Que forma assume a montanha? Como se distribuem suas vertentes, qual é o formato da cumeeira? Aqui já aparece, de maneira subentendida, uma relação de causa e efeito: a cada formato de placa corresponde uma forma para a montanha de areia. Está presente aí, inusitadamente, o conceito de função, com domínio no conjunto de formas planas (as placas) e contradomínio no conjunto de formas tridimensionais (as montanhas). Essa compreensão pode ser explicitada para alunos do Ensino Médio que estão às voltas com definições formais do que é uma função e ainda carecem de certa diversidade de exemplos.

No entanto, independentemente do público, cabe perguntar, de início, qual será a forma da montanha quando a placa for um círculo ou um quadrado. A resposta nem sempre é imediata, mas admite-se que é intuitiva: um cone no primeiro caso e uma pirâmide no segundo. São formas conhecidas, mas discutidas num contexto inédito para todos. Em seguida, quando as placas são triângulos, retângulos ou elipses, começa a ficar mais difícil adivinhar o resultado, fazendo-se necessária a verificação experimental.

Um aspecto que se destaca nas formas das montanhas é a cumeeira. No cone ela se reduz a um ponto, o cume, que se projeta verticalmente sobre o centro da placa circular. Na pirâmide são os quatro segmentos de reta que unem o cume aos vértices da base quadrada, que se projetam sobre as duas diagonais do quadrado. Chama-se "esqueleto" essa coleção de linhas imaginárias sobre a placa que são formadas pela projeção vertical da cumeeira.

O conhecimento do conceito de bissetriz, que normalmente é visto no período do Fundamental II, permite prever o esqueleto de polígonos. O esqueleto é formado por segmentos de reta contidos nas bissetrizes entre as retas que se apoiam nas arestas do polígono, mesmo que não sejam adjacentes entre si.

Para aqueles que conhecem parábolas e como elas são definidas, é possível entender por que aparecem segmentos de parábola no esqueleto de placas poligonais não convexas e de placas poligonais com furos circulares no meio.

$O$ conceito de função reaparece ainda de outra maneira. Ao saturar de areia, a inclinação da encosta assume o valor máximo para o qual não há deslizamentos. $\mathrm{O}$ valor dessa inclinação depende das propriedades físicas da areia. Essa inclinação constante faz com que a altura da montanha sobre cada ponto da placa seja proporcional à sua distância ao bordo. Ou seja, a montanha é essencialmente o gráfico da função "distância ao bordo" definida sobre os pontos da placa.

Essa função distância é de grande interesse em aplicações, como Óptica, Visão Computacional e Robótica. Mas ela também está envolvida no conceito de "centro geográfico”, que é definido como o ponto mais distante da fronteira. No experimento com areia é o ponto da placa verticalmente abaixo do ponto mais alto da montanha. Para mostrar isso, há placas com os mapas do Brasil (Figura 8) e do Estado de São Paulo. As pessoas são convidadas a adivinhar a localização de seus centros geográficos e depois podem verificar seus palpites despejando areia sobre a placa e marcando o ponto mais alto da montanha com um palito.

Há também discussões mais avançadas, para os, digamos, "iniciados”. Por exemplo, o esqueleto do quadrado tem um ponto onde incidem quatro vertentes, mas é possível provar que isso é uma "coincidência", no sentido de que pequenas alterações no 
formato do bordo fazem com que esse ponto se transforme em dois, cada um com três vertentes, sendo uma delas em comum.

Nessa infinita gama de possibilidades de abordagem e de assuntos que podem derivar de uma atração, é imprescindível o papel dos monitores, que são recrutados entre os alunos de graduação e até mesmo de pós-graduação. Os monitores acabam tendo contato tanto com o público leigo quanto com pessoas que têm a ensinar sobre a matemática das peças. Conseguem assim se manter atualizados e interessados e usam essa experiência para criar novas formas de explicação e de motivação para o público.

\section{FORMAS DE MOTIVAR}

Um segundo ponto que se apresentou nessa caminhada foi relativo a outra diversidade: a dos interesses do público. As pessoas têm diferentes interesses e sensibilidades e cabe ao divulgador encontrar no assunto exposto uma ampla gama de aspectos, de forma a ter possibilidade de utilizar variados meios para conquistar o interesse do visitante. Na coleção de atrações da Matemateca, alguns desses aspectos são contemplados. Listemos três deles.

Beleza - Aqui está-se referindo à beleza das formas, porque é essa que pode ser transmitida mais rapidamente num ambiente expositivo. Não se deve excluir, no entanto, a beleza que é estrutural e mais abstrata, evidenciada pela maneira surpreendente como conceitos aparentemente distantes se relacionam.

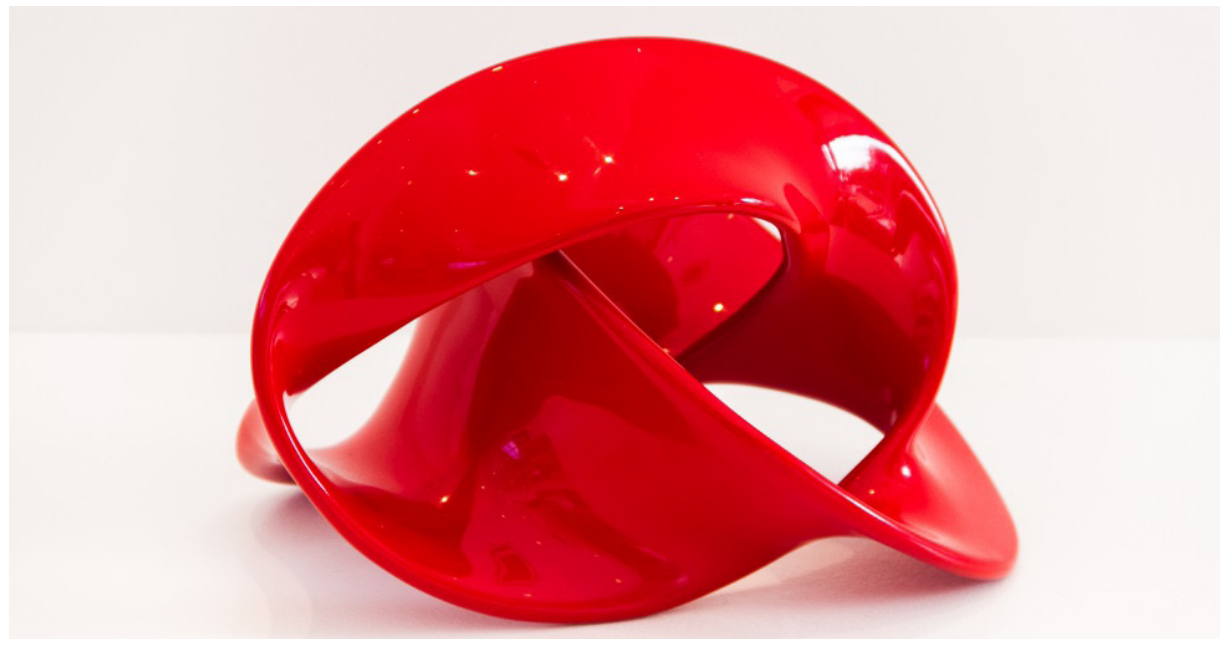

Nessa categoria, destacam-se não só os poliedros, mais familiares aos visitantes, mas também as superfícies, abordadas sob o ponto de vista de uma área pouco conhecida do público, a Topologia (Figura 9). Nessa teoria, as superfícies são vistas por suas propriedades mais intrínsecas, que são mantidas mesmo sob deformações (um bola murcha e uma bola "cheia" são iguais), diferentemente da Geometria, que
Figura 9 - Superfícies sob o ponto de vista topológico. Aqui a beleza está associada não apenas ao material de execução das peças, mas às características surpreendentes dessas formas inusitadas e pouco encontradas em nosso dia-a-dia 
se preocupa com a forma exata dos objetos no espaço. As superfícies topológicas vistas na foto acima fazem muito sucesso junto ao público e não raro, algum visitante pergunta onde "comprar" uma superfície. A curiosidade despertada pela beleza ou pelo inusitado da forma dá a abertura esperada para contar porque os matemáticos se interessam por estas formas e como pensam sobre elas.

O lúdico, o desafio - Muitos gostam de jogar: o jogo que não é pura sorte envolve raciocínio, e esse é um aspecto importante na atividade matemática. Alguns preferem desafios individuais, de autossuperação, outros da competição contra um adversário. De qualquer maneira, isso tem tudo a ver com algo que é muito caro ao universo matemático: o desejo de resolver um problema.

A exposição conta com algumas versões do Jogo da Velha: a tradicional, num ta-

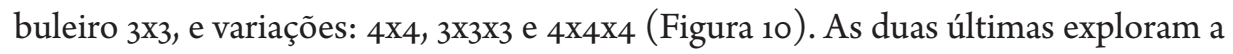
tridimensionalidade, portanto entender o que é uma "linha" nesses dois casos já é algo interessante para despertar a visualização geométrica. No Jogo da Velha tradicional, ambos os jogadores podem evitar perder, se jogarem corretamente. Ou seja, existe uma estratégia de empate para ambos, mas nenhum deles tem um jeito de ganhar com

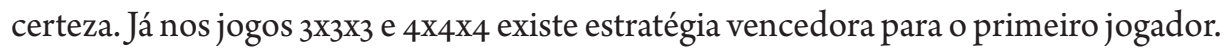
Isto significa que, não importa como jogue o segundo jogador, se o primeiro jogador conhecer a estratégia e jogar de acordo, ele vai ganhar. Essa estratégia é até fácil no caso $3 \times 3 \times 3$, mas nada óbvia no caso $4 \times 4 \times 4$. Dentro da Matemática essas questões são estudadas na Teoria dos Jogos. Essa área é de grande interesse para a Economia. Tanto é que grandes matemáticos, como o famoso John Nash, para citar um exemplo, ganharam o Prêmio Nobel de Economia por trabalhos nessa área.

\footnotetext{
Figura 10 - Jogo da Velha no tabuleiro de $4 \times 4 \times 4$ casas, que generaliza o Jogo da Velha tradicional. O conceito de "linha" tem que ser reaprendido e as estratégias de jogo se tornam menos óbvias.
}

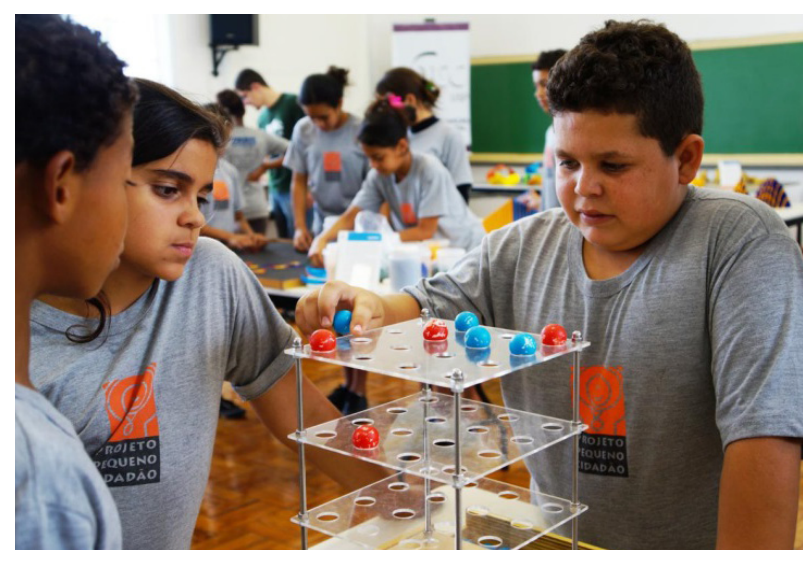

Presença nosfenômenos do mundo - O poder mais reconhecido da Matemática reside no fato de ser a linguagem que permite descrever o mundo físico. E isso é a base das aplicações tecnológicas, que nascem desse entendimento. No exemplo acima citado das Montanhas de Areia, percebe-se claramente a transição entre a observação pura e simples de um fenômeno até a sua completa transformação em problemas matemáticos, que podem ser resolvidos por argumentos geométricos. 
Um dos mistérios mais fascinantes da presença matemática no mundo físico é a presença universal da chamada distribuição normal. Medidas experimentais, mesmo sofrendo com a incerteza, teimam em se ajustar aos desígnios dos histogramas em forma de sino. $\mathrm{O}$ pioneiro Francis Galton criou até um aparato mecânico para ilustrar o fenômeno, que denominou de quincux. É um tabuleiro em que um conjunto de bolinhas escorre entre obstáculos e cai, em sua parte inferior, mostrando ser mais provável ficar no meio do que nas pontas (Figuras 11(a-d) e 12).
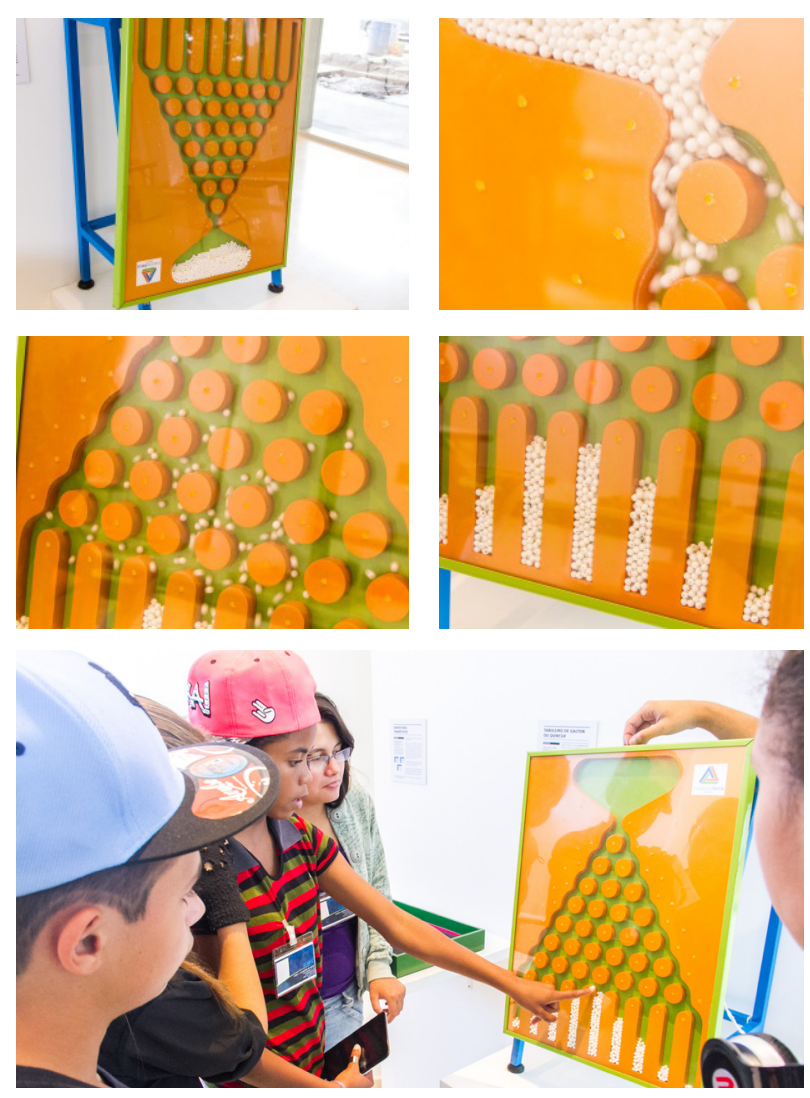

Figuras 11(a-d) e 12 - Quincux, o tabuleiro inventado por Francis Galton. Quando virado na posição contrária à que aparece na Figura 10(a) as bolinhas se distribuem nas canaletas de maneira não uniforme, com mais presença no meio e menor presença nas pontas, como é ilustrado na Figura 10(d)

Essa variabilidade de aspectos de atração não esgota as possibilidades de conquista do público, mas apresenta ao menos uma reflexão preliminar. É importante que o visitante se sinta bem vindo, sejam quais forem seus interesses pessoais, goste ou não de Matemática. Afinal, se a intenção é mudar o que as pessoas pensam sobre a Matemática e alargar os horizontes do que é percebido como assunto da Matemática, o primeiro passo é acolher a todos!

$\mathrm{Na}$ construção desse acolhimento e do despertar da curiosidade, o monitor tem um papel de extrema importância. Num primeiro contato com a exposição o visitante muitas vezes se mostra reticente, quase que receoso de chegar muito perto. Afinal, trata-se de Matemática! Cabe ao monitor recepcionar o visitante, convidá-lo a tocar nos objetos, deixá-lo à vontade para brincar um pouco. É também papel do monitor 
provocar a curiosidade, lançar um desafio quando sente que pode ir mais além. Nossos monitores são nossos alunos de graduação e pós-graduação e têm feito um belo trabalho, inclusive treinando e preparando novas gerações de monitores, com pouca intervenção da parte dos professores da equipe.

\section{AONDE MAIS SE PODE IR?}

De maneira geral, a experiência adquirida nos primeiros 10 anos de Matemateca se mostrou muito rica, revelando que é possível apresentar ao público geral a Matemática mais parecida com o que ela é para os matemáticos e não como ela se cristalizou nos bancos escolares. É importante frisar que numa exposição dessas não se pretende ensinar matemática, apenas motivar. Um visitante que sai da exposição sem ter aprendido absolutamente nada, porém muito curioso a respeito das coisas que viu é um grande sucesso! É claro que o aprendizado é uma consequência desse processo, mas ele não é o foco principal de atenção. Uma exposição como essa não dispensa a prática escolar, mormente a resolução de exercícios e o estudo organizado.

Na Matemateca todos os objetos podem ser tocados e têm funcionamento mecânico. No linguajar de hoje, é uma exposição “analógica”. A ausência de interatividade tecnológica não é exatamente uma escolha, uma vez que esse tipo de atração é mais custoso e de difícil manutenção e portabilidade. Os autores acham, no entanto, que a interatividade tecnológica não é uma panacéia e que deve ser usada apenas quando necessária, conservando o equilíbrio entre formas clássicas e modernas. A escolha, quando possível, deve ser feita em função daquilo que se quer comunicar. Acreditam também que há mais surpresa nas interações que não necessitam de um computador para se realizarem, uma vez que a existência sabida de um software no controle da atração pode, essencialmente, dar a sensação de que se pode fazer qualquer coisa. Assim, transfere-se para um misterioso "programa" a capacidade de realizar o que quiser, e a Matemática perde força, escondida no artifício tecnológico.

Os autores tiveram a oportunidade de trabalhar com equipes multidisciplinares que ajudaram a descortinar todo um universo de planejamento de exposição. Em especial com a produtora cultural Thais Teixeira, um convívio muito rico de aprendizados revelou muitas possibilidades para a exposição da Matemateca. No passado, partimos de objetos que achamos interessantes e ricos do ponto de vista matemático para, depois de conseguir um acervo razoável, pensar na organização de uma exposição. O que podemos fazer agora é inverter o processo e pensar, em primeiro lugar, na mensagem que queremos passar para, a partir daí, delinear um percurso a ser seguido pelo visitante na construção dessa mensagem, e então, finalmente, criar as atrações em função do papel que devem desempenhar nesse percurso. Além de ser uma evolução que parece natural para a exposição da Matemateca, é interessante observar que essa proposta mimetiza a transformação histórica experimentada por muitos museus que, partindo da função principal de guardar e preservar objetos, passaram a expô-los ao público e, posteriormente, a tentar explicar e dar contexto a essa exposição para, finalmente, dar ao público o papel de protagonista e planejar a exposição em função 
daquele a quem se pretende atingir [11]. Até agora essa opção não foi considerada por razões mais ligadas à logística e ao fato de a Matemateca não dispor de um local para manter uma exposição permanente.

Há um rico caminho a seguir no terreno das exposições sobre Matemática, tanto na criação de novas atrações como na forma de expô-las para o público. Por outro lado, ao longo destes dez anos a Matemateca construiu um acervo importante e adquiriu uma expertise em divulgação científica que será mais bem aproveitada quando se dispuser de um local para manter uma exposição permanente aberta ao público em geral e aos estudantes de escolas públicas em especial.

\section{REFERÊNCIAS}

[1] ACZEL, A. The artist and the mathematician: the story of Nicolas Bourbaki, the genius mathematician who never existed. London: High Stakes Publishing, 2007.

[2] BELLOS, A. Alex no país dos números. São Paulo: Companhia das Letras, 2011.

[3] COURANT, R. e Robbins, H. O que é matemática? Rio de Janeiro: Ciência Moderna, 2000.

[4] CRATO, N. Passeio aleatório. Portugal: Gradiva, 2007.

[5]_. A matemática das coisas. Portugal: Gradiva, 2008.

[6] DEVLIN, $\mathrm{K}$. The language of mathematics: making the invisible visible. New York: Holt Paperbacks, 1998.

[7] . O gene da Matemática. Rio de Janeiro: Record, 2004.

[8] GARDNER, M. The colossal book of mathematics. New York: W. W. Norton \& Company, 2001.

[9] GLEICK, J. Caos, a criação de uma nova ciência. Rio de Janeiro : Campus, 1990.

[10] A informação. São Paulo : Companhia das Letras, 2011.

[11] GOB, A. E DROUGUET, N. La muséologie: histoire, développements et enjeux actuels. Paris: Armand Colin, 2010.

[12] KNIGHT, D. M. Scientists and their publics: popularization of science in the nineteenth century. In: [A. do livro] M. J. Nye. The modern physical and mathematical sciences. New York: Cambridge University Press, 2002, pp. 72-90.

[13] MASHAAL, M. Bourbaki: a secret society of mathematicians. Providence: American Mathematical Society, 2006.

[14] STEWART, I. Uma história da simetria na matemática. Rio de Janeiro: Zahar, 2012.

[15] . 17 equações que mudaram o mundo. Rio de Janeiro: Zahar, 2013.

[16] TAHAN, M. O homem que calculava. Rio de Janeiro: Record, 2003.

[17] THE SCIENCE MUSEUM BLOG. Disponível em: <http://blog.sciencemuseum.org.uk/insight/tag/david-and-claudia-harding-mathematics-gallery/>. Acesso em: 17 ago. de 2015. 
EDUARDO COLLI professor do Instituto de Matemática e Estatística da Universidade de São Paulo (IME-USP), diretor do Centro de Difusão e Ensino Matemateca e participante do programa Aventuras na Ciência - e-mail:colli@ime.usp.br

DEBORAH RAPHAEL professora do Instituto de Matemática e Estatística da Universidade de São Paulo (IME-USP) e vice-diretora do Centro de Difusão e Ensino Matemateca - e-mail: raphael@ime.usp.br 